\title{
Role of Paleomagnetism in the Construction of Earth's Geographic Past
}

Stephanie Robinson

University of South Florida, sjrobinson@usf.edu

\author{
Advisors: \\ Arcadii Grinshpan, Mathematics and Statistics \\ Joseph Panzik, School of Geosciences \\ Sarah Sheffield, School of Geosciences \\ Problem Suggested By: Joseph Panzik and Sarah Sheffield \\ Field of Study for Problem Suggester: School of Geosciences
}

Follow this and additional works at: https://digitalcommons.usf.edu/ujmm

Part of the Mathematics Commons

UJMM is an open access journal, free to authors and readers, and relies on your support:

Donate Now

\section{Recommended Citation}

Robinson, Stephanie (2020) "Role of Paleomagnetism in the Construction of Earth's Geographic Past," Undergraduate Journal of Mathematical Modeling: One + Two: Vol. 11: Iss. 1, Article 2.

DOI: https://doi.org/10.5038/2326-3652.11.1.4921

Available at: https://digitalcommons.usf.edu/ujmm/vol11/iss1/2 


\title{
Role of Paleomagnetism in the Construction of Earth's Geographic Past
}

\begin{abstract}
Rocks have the ability to preserve magnetic information used in determining past geographic formations. The purpose of this report is to determine the past location of a site from a given data set's magnetic information and the calculations found through their application to paleomagnetism. Magnetic information includes the rock sample's location and concentration of trace magnetic particles which were used to find declination and inclination on site. The sample's paleolatitude and paleolongitude are calculated using trigonometric equations that are derived using calculus. After a statistical analysis, these results are compared to the present day's magnetic poles to determine the past location of the site. This location, along with the magnetic information, is combined to construct a past geographic formation that existed a billion years ago. This process reveals that the site currently found in southwest Namibia, was located near the coast of modern-day northwest Africa during the late Mesoproterozoic Era within a 95\% certainty. When compared to past literature these results show the reliability and role of paleomagnetism, as well as the importance of collaboration across the geosciences.
\end{abstract}

\section{Keywords}

paleomagnetism, past geographic formation, rock sample

\section{Creative Commons License}

(c) $($ ) $\odot$

This work is licensed under a Creative Commons Attribution-Noncommercial-Share Alike 4.0 License. 


\section{PROBLEM STATEMENT}

Based on a given data set, properly explain how magnetic information is derived from rock samples and demonstrate the utilization of calculus to find mathematical formulas used in paleomagnetism. Then calculate, using found equations and statistical analysis, the location of the original sample site and illustrate its role in constructing past geographic formations.

\section{MOTIVATION}

Understanding the past helps us to better prepare for the future. One way to gain pertinent information on past events and environments is through paleomagnetism. Paleomagnetism can be defined as, “... the study of the magnetic properties of rocks." (Tauxe et al., 2010). A rock's natural remanent magnetization (NRM) can be measured using a magnetometer or through the process of demagnetization and be compared to Earth's current magnetic field to determine changes in Earth's geological history (McElhinny \& McFadden, 2000). Human use of magnetics dates back thousands of years, from the mystification surrounding lodestones, to the utilization of naturally magnetic materials in navigation (Prothero, 2018). In 1600, William Gilbert's De Magnete hypothesized the magnetic field on a global scale (Figure 1) - which began the study of Earth's relationship to magnetism (Prothero, 2018). As our understanding of the magnetic field progresses and advancements in technology are made, the study of paleomagnetism is developed.

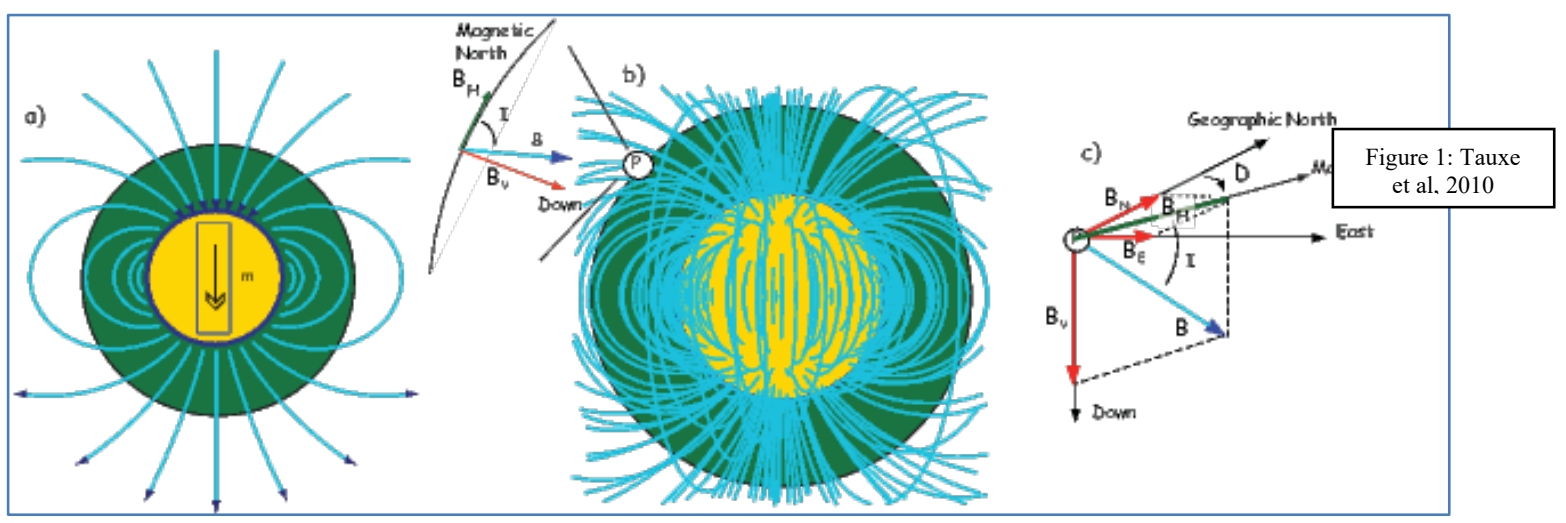




\section{Magnetics, Paleomagnetism \& their Connections to Geoscience}

Subatomic particles consist of negatively charged electrons, positively charged protons and neutral neutrons (Urry, 2020). The movement of these electrical charges create magnetic fields (shown in Figure 2), consisting of vectors with distinct poles (Campbell, 2017). Materials contain magnetic fields when the subatomic particles are not cancelling each other's electrical charge - cancellation of charge occurs when the particles are in an even ratio and spinning in opposite directions (Campbell, 2017).

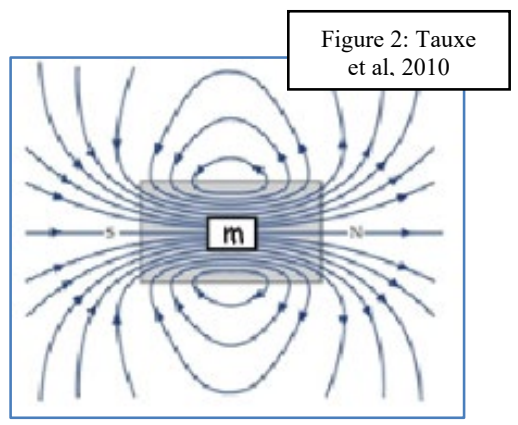

Magnetic materials are categorized into non-ferromagnetic (diamagnetic (negative attraction away from magnetic fields) and paramagnetic (positive attraction towards magnetic fields)) and ferromagnetic (magnetic field occur due to absence of applied field (antiferromagnetic, ferrimagnetic or ferromagnetic due to spin alignment)) based on how the trace particles act (Tauxe et al., 2010). Examples of these magnetic materials include magnetite $\left(\mathrm{Fe}_{3} \mathrm{O}_{4}\right)$, greigite $\left(\mathrm{Fe}_{3} \mathrm{~S}_{4}\right)$ and pyrrhotite $\left(\mathrm{Fe}_{7} \mathrm{~S}_{8}\right)$, which all are compounds that contain iron (Tauxe et al., 2010). When rock is originally formed, these trace particles orient themselves based on the earth's poles. Over time, the trace particles remain, preserving information about the rock's original location. As the rock is moved and changed due to continental drift, natural climatic changes and additional formations, new trace particles document new orientations based on the earth's poles. Because of this phenomenon magnetometers and demagnetization (method of heating present rock past its Curie temperature to find NRM) can measure a rock's NRM (Tauxe et al., 2010). When a rock sample is taken, its current location, NRM, declination $(D)$ and inclination $(I)$ are taken to determine the rock sample's past location (based on pole and site paleolongitude and paleolatitude).

The geocentric axial dipole (GAD), shown in Figure 3, is the model that paleomagnetic calculations are based on (Jacobs, 1987). This model depicts an Earth with a single magnetic dipole that creates the earth's magnetic field (Jacobs, 1987). Despite the fact that, due to slight discrepancies in the natural world, the earth does not adhere perfectly to the GAD (Figure 4), the surface of the earth's magnetic field is primarily made up of a dipole $(l$, order 1$)$ allowing GAD to be assumed (Tauxe et al., 2010).

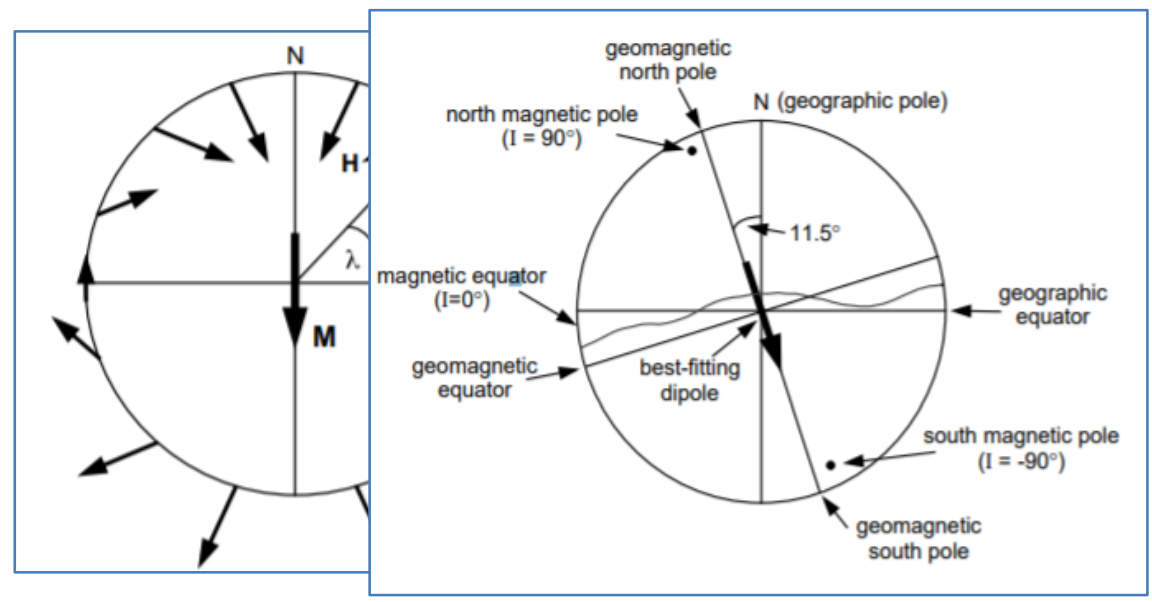


Beginning with Alfred Wegener in the early $20^{\text {th }}$ century, scientists began to approach the theory of continental drift - evidence of similar bedrock beneath differing continents, as well as the dispersal of animals and climates across the globe puzzled many (Jacobs, 1987). It was not until Marie Tharp's mid-century discovery of ocean-floor spreading that the theory was widely accepted. Using magnetometers, Bruce Heezen's and her observatory showed the magnetic patterns in the ocean-floor through paleomagnetism to support the spreading of tectonic plates (Jacobs, 1987).

Since tectonic plates move, we can use methods, like the one Marie Tharp used in the 1950s, to map geographic locations of previous landmasses throughout Earth's history. An understanding of Earth's magnetic field allows its poles to serve as references to the preserved sample's apparent magnetic pole. Paleomagnetism needs many samples to produce substantial results and requires assistance from calculus and geology to interpret the magnetic patterns found in said samples. This holistic approach gives researchers context - which proves to be extremely crucial in paleomagnetism. In addition to macro changes in geographic location of continents, Earth's dipoles slightly move overtime (shown in Figure 4, within a 10 to 11-degree diameter circle). To account for this, paleomagnetism applies apparent polar wander (APW), which is the accumulation of discrepancies created by continental drift and gradual pole movement, shown in Figure 5 (Tauxe et al., 2010).

Paleomagnetism is beneficial to a multitude of scientific fields including, "...geomagnetism, tectonics, paleoceanography, volcanology, paleontology, and sedimentology." (Tauxe et al., 2010). Being able to determine and interpret magnetic information from rock samples and apply paleomagnetic formulas to construct past geographic formations is important to a variety of geosciences and practices.

Paleomagnetic data is used in climate science to study paleoclimatology to see how our climate compares to those of the past (Barendregt et al., 2010). Figure 6 shows data as an example of this - where paleomagnetic data, along with geologic data (i.e., sediment type) allowed researchers to better document glacial periods during the Cenozoic era (Barendregt et al., 2010).

The field of paleomagnetism is relevant today, as scientists continue to piece together landmasses of the past to

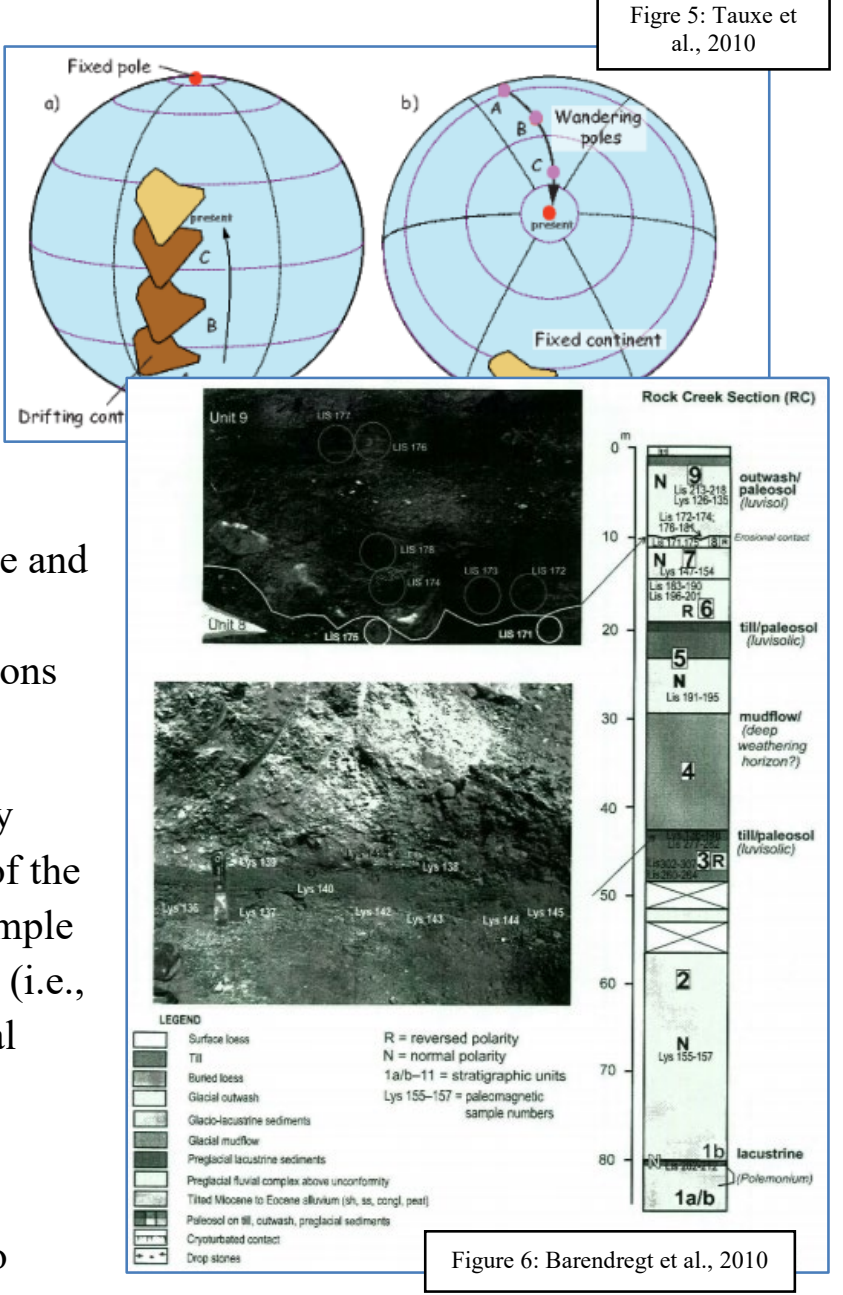
learn how the planet works (i.e., mechanisms of plate tectonics). This report's given 
data set is based on a study conducted in Namibia, Africa (Panzik et al., 2015). This work allowed for geophysicists to better understand the geographic formation of the earth over a billion years ago.

This report will discuss how calculus can be used within the field of paleomagnetism to construct geographic formation from 1.105 billion years ago $(\mathrm{Ga})$ based on rock samples found in 2011 and 2012. Its main objectives are to properly explain how magnetic information is derived from rock samples, demonstrate the utilization of calculus to find mathematical formulas used in paleomagnetism, calculate (using found formulas and statistical analysis) the coordinates of the original sample's location and show the role of this location in constructing a past geographic formation.

\section{MATHEMATICAL DESCRIPTION AND SOLUTION APPROACH}

The construction of past geographic formations can be created by the summation of many rock sample's paleolongitudes and paleolatitudes. To find these values, paleomagnetism applies the properties of magnetic induction $(\vec{B})$, defined as a measure of a magnetic field's strength, to Earth's magnetic field (found with its magnetic potential $\left(\Psi_{m}\right)$ ), which is made up of radial $\left(B_{r}\right)$, polar $\left(B_{\theta}\right)$ and longitudinal $\left(B_{\phi}\right)$ components (Tauxe et al., 2010). Equation (1) shows the relationship between magnetic induction $(\vec{B})$, permeability of free space (a constant, $\mu_{0}(4 \pi$ $\left.\mathrm{x} 10^{-7} \frac{H}{m}\right)$ ), magnetic field $(\vec{H})$ and the magnetic dipole moments (magnetization $(\vec{M})$ ).

$$
\text { (1) } \vec{B}=\mu_{0}(\vec{M}+\vec{H})
$$

The magnetization $(\vec{M})$ of a magnetized body varies in value based on location - outside of a magnetized body, magnetization $(\vec{M})$ equals 0 since there is no consideration of the magnetic particles outside of the magnetized body (Tayxe et al., 2010). Because of this phenomenon, we can simplify our Equation (1) by equating magnetization $(\vec{M})$ to 0 since the earth acts as a magnetized body (this is shown in Figure 7).

$$
\text { (2) } \vec{B}=\mu_{0} \vec{H}
$$

The magnetic field $(\vec{H})$ can be written as a gradient of a scalar field, represented by the magnetic potential $\left(\Psi_{m}\right)$, to be placed within a spatial gradient $(\vec{\nabla})$ consisting of $\frac{d}{d x}, \frac{d}{d y}, \frac{d}{d z}$.

$$
\text { (3) } \vec{H}=-\vec{\nabla} \Psi_{m}
$$

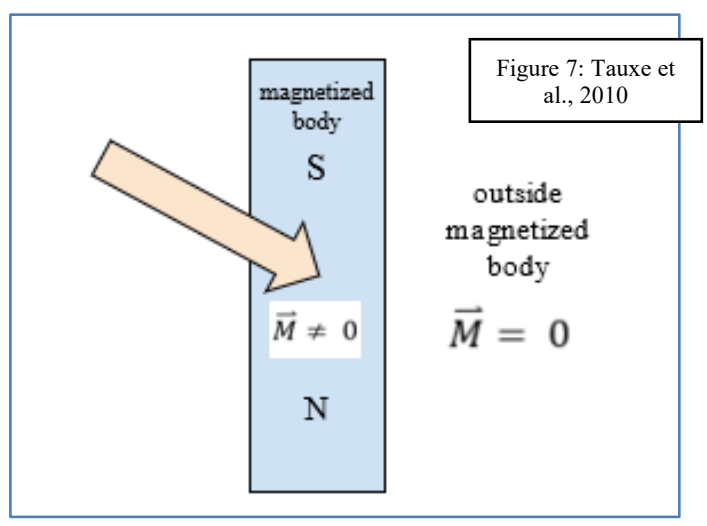


The earth's magnetic potential $\left(\Psi_{m}(r, \theta, \phi)\right)$ can be found by Equation (4). Figure 8 and 9 show the application of the Schmidt polynomials (Tauxe et al., 2010).

(4) $\Psi_{m}(r, \theta, \phi)=\frac{a}{\mu_{0}} \sum_{l=1}^{\infty} \sum_{m=0}^{l}\left(\frac{a}{r}\right)^{l+1} P_{l}^{m}(\cos (\theta))\left(g_{l}^{m} \cos \left(m_{\phi}\right)+h_{l}^{m} \sin (m \phi)\right)$

$P_{1}^{0}=\cos \theta, P_{2}^{0}=\frac{1}{2}\left(3 \cos ^{2} \theta-1\right)$, and $P_{3}^{0}=\frac{1}{2} \cos \theta\left(5 \cos ^{3} \theta-3 \cos \theta\right)$

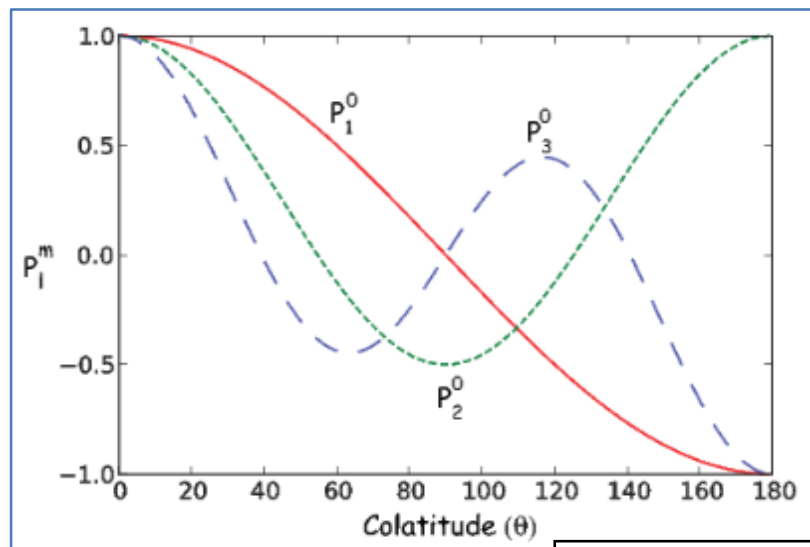

Figure 9: Tauxe et al., 2010

\begin{tabular}{|c|l|}
\hline$\Psi_{m}$ & magnetic potential \\
\hline$a$ & $\begin{array}{l}\text { radius of Earth }\left(6.371 \times 10^{6} \mathrm{~m} \text { (Taxue et }\right. \\
\text { al., 2010) })\end{array}$ \\
\hline$r$ & radial distance \\
\hline$\theta$ & co-latitude (angle from N pole) \\
\hline$\phi$ & longitude \\
\hline$l$ & degree of coefficient \\
\hline$m$ & order of coefficient \\
\hline$P_{l}^{m,}$ & $\begin{array}{l}\text { partially normalized Schmidt } \\
\text { polynomials }\end{array}$ \\
\hline$g_{l}^{m,}$ & Zonal Gauss Coefficient \\
\hline
\end{tabular}

However, Equation (4) can be simplified tremendously, because we treat the earth's magnetic field as a geocentric axial dipole (GAD) where $l=1$ and $\mathrm{m}=0$. Simplified Equation (4):

(5) $\Psi_{m}(r, \theta, \phi)=\frac{a}{\mu_{0}}\left(\frac{a}{r}\right)^{2} P_{l}^{m}(\cos (\theta))\left(g_{l}^{m} \cos (0)+h_{l}^{m} \sin (0)\right)$ 
(6) $\Psi_{m}(r, \theta, \phi)=\frac{a^{3}}{r^{2} \mu_{o}} P_{1}^{o}(\cos (\theta))\left(g_{1}^{0}\right)$ and if $P_{1}^{o}(\cos (\theta))=\cos (\theta)$ then,

$$
\text { (7) } \Psi_{m}(r, \theta, \phi)=\frac{a^{3}}{r^{2} \mu_{o}} \cos (\theta)\left(g_{1}^{0}\right) \text {. }
$$

Recall from Equations (2) and (3) that $\vec{B}=\mu_{0} \vec{H}$ and $\vec{H}-\vec{\nabla} \Psi_{m}$. We can now rewrite magnetic induction $(\vec{B})$ as Equation (8):

$$
\text { (8) } \vec{B}=-\mu_{0} \vec{\nabla} \Psi_{m}
$$

Earth uses spherical coordinates, so Earth's magnetic induction $(\vec{B})$ consists of the spherical coordinates, $B_{r}, B_{\theta}, B_{\phi}$. We can present each component differently:

(9) Radial Component: $B_{r}=-\frac{\mu_{0} \partial \Psi_{m}}{\partial r}=-\frac{\mu_{0} a^{3}}{\mu_{0}}, g_{1}^{0} \cos (\theta) \frac{\partial}{\partial r}\left(\frac{1}{r^{2}}\right)=\frac{2 g_{1}^{0} a^{3} \cos (\theta)}{r^{3}}$ which can be simplified to: $B_{r}=2 g_{1}^{0} a^{3} \frac{\cos (\theta)}{r^{3}}$,

(10) Polar Component: $B_{\theta}=-\frac{\mu_{0}}{r} \frac{\partial \Psi_{m}}{\partial \theta}=-\frac{\mu_{0}}{r} \frac{a^{3}}{\mu_{0} r^{2}} g_{1}^{0} \frac{\partial}{\partial \theta} \cos (\theta)=\frac{g_{1}^{0} a^{3} \sin (\theta)}{r^{3}}$ which can be simplified to: $B_{\theta}=g_{1}^{0} a^{3} \frac{\sin (\theta)}{r^{3}}$ and,

$$
\text { Longitudinal Component: } B_{\phi}=-\frac{\mu_{0}}{\sin (\theta)} \frac{\partial \Psi_{m}}{\partial \phi}=-\frac{\mu_{0}}{r \sin (\theta)} \frac{\partial}{\partial \phi}\left(\frac{a^{3}}{\mu_{0} r^{2}} g_{1}^{0} \cos (\theta)\right)
$$

which can be simplified to: $B_{\phi}=0$ because $\phi$ is considered a constant and the derivative of a constant is 0 .

The radius of the earth $(a)$ is our radius $(r)$ here, so we can simplify equations 9 and 10:

$$
\begin{gathered}
B_{r}=\frac{2 g_{1}^{0} a^{3} \cos (\theta)}{a^{3}}=2 g_{1}^{0} \cos (\theta) \\
B_{\theta}=\frac{g_{1}^{0} a^{3} \sin (\theta)}{a^{3}}=g_{1}^{0} \sin (\theta)
\end{gathered}
$$

We can now say that the radial component $\left(B_{r}\right)$ is equal to $2 g_{1}^{0} \cos (\theta)$ and the polar component $\left(B_{\theta}\right)$ is equal to $g_{1}^{0} \sin (\theta)$. Inclination $(I)$ can be defined as the angle that the magnetic conduction $(\vec{B})$ makes with ground (shown in Figure 10) and ranges from $-90^{0}$ degrees to 
$+90^{\circ}$ (Tauxe et al., 2010). While declination $(D)$, shown in Figure 11, is the angle that the magnetic conduction $(\vec{B})$ makes away from north pole - this is the angle that compasses read (Tauxe et al., 2010).
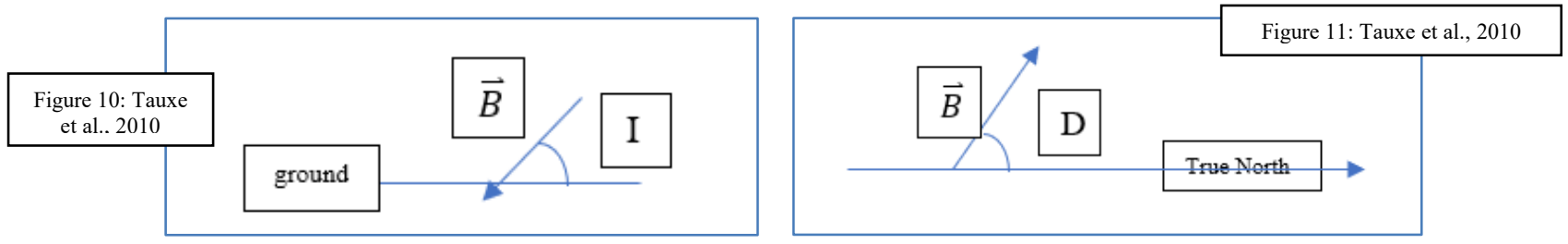

As previously stated, geocentric axial dipole (GAD) has properties that allow us to approach Earth's magnetic field. Under the context of GAD, we can assume that declination $(D)$ is equal to 0 , since $B_{\phi}=0$. The angle created by declination $(D)$ is shown in Figure 12, while inclination $(I)$ is shown in Figure 13.
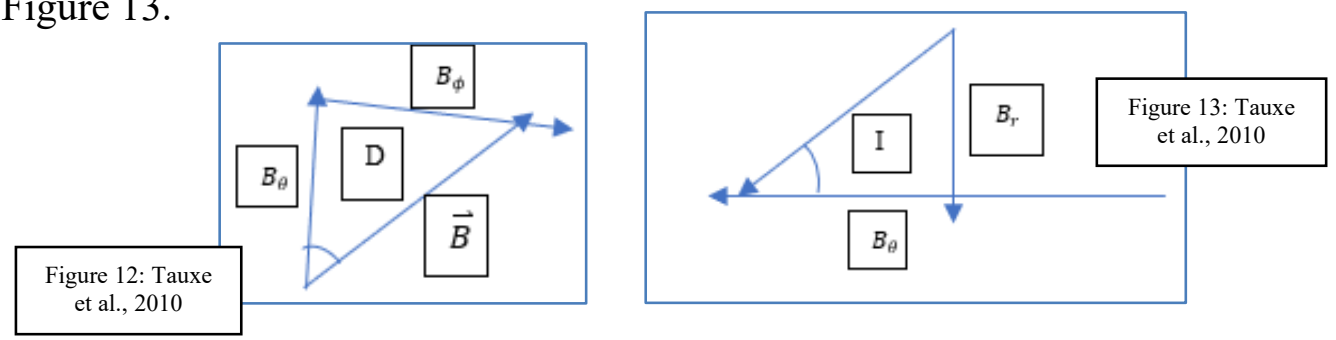

If $\frac{\sin (\theta)}{\cos (\theta)}=\tan (\theta)$ and $g_{1}^{0}=1\left(\frac{n !}{k !(1-k) !}\right.$ when $\mathrm{n}=0$ and $\mathrm{k}=1$ is equal to $\left.\frac{1}{1 ! 1 !}=1\right)$ then Equation (14) and (15) depict how we can calculate declination $(D)$ and inclination $(I)$.

$$
\begin{aligned}
& \tan (D)=\frac{B_{\phi}}{B_{\theta}}=\frac{0}{\sin (\theta)}=\tan ^{-1}(0)=0 \\
& \text { (15) } \tan (I)=\frac{B_{r}}{B_{\theta}}=2 \frac{\cos (\theta)}{\sin (\theta)}
\end{aligned}
$$

To convert from polar coordinates to latitudinal coordinates we can use $\theta=90-\lambda$, where $\lambda$ is latitude. This allows us to show that $\cos (\theta)=\cos (90-\lambda)=\sin (\lambda)$ and $\sin (\theta)=\sin (90-\lambda)=\cos (\lambda)$,

$$
\text { so } \tan (I)=2 \frac{\sin (\lambda)}{\cos (\lambda)}=2 \tan (\lambda)
$$

From these formulas, paleomagnetism can measure inclination $(I)$ and declination $(D)$ of samples. Declination $(D)$ provides orientation, while inclination $(I)$ provides latitude (Tauxe et al., 2010). If $\lambda_{p}=$ pole latitude, $\lambda_{s}=$ site latitude, $\phi_{p}=$ pole longitude, $\phi_{s}=$ site longitude and $\theta=$ magnetic co - latitude, then we can calculate the information the sample contains about past geographic location using found declination $(D)$ and inclination $(I)$ :

$$
\tan (\mathrm{I})=2 \frac{\cos (\theta)}{\sin (\theta)}=2 \tan ^{-1}(\theta) ; \theta=\tan ^{-1}\left(\frac{2}{\tan (I)}\right)
$$


Using spherical geometry, we can say that:

$$
\lambda_{p}=\sin ^{-1}\left(\sin \left(\lambda_{s}\right) \cos (\theta)+\cos \left(\lambda_{s}\right) \sin (\theta) \cos (D)\right) \text { (Tauxe et al., 2010). }
$$

We cannot determine paleolongitude of both pole $\left(\phi_{p}\right)$ and site $\left(\phi_{s}\right)$ using the same method that we used for paleolatitude (for both pole $\left(\lambda_{p}\right)$ and site $\left(\lambda_{s}\right)$ ). This alternative approach determines where the paleolongitude for both pole $\left(\phi_{p}\right)$ and site $\left(\phi_{s}\right)$ are located:

$$
\begin{gathered}
\cos (\theta) \geq \sin \left(\lambda_{s}\right) \sin \left(\lambda_{p}\right) \text { then }\left(\phi_{p}=\phi_{s}+\beta\right) \text { and } \\
\cos (\theta)<\sin \left(\lambda_{s}\right) \sin \left(\lambda_{p}\right) \text { then }\left(\phi_{p}=180^{\circ}+\phi_{s}-\beta\right) .
\end{gathered}
$$

$\beta$, the longitudinal difference between pole and site, is represented by Equation (21). This is used to calculate the paleolongitudes (Equations (19) and (20)).

$$
\beta=\sin ^{-1}\left(\frac{\sin (\theta) \sin (D)}{\cos \left(\lambda_{p}\right)}\right)
$$

\section{Application of Data Set}

Dr. Joseph Panzik of the USF School of Geosciences provided a data set collected during the summers of 2011 and 2012 in Namibia, Africa (Panzik et al., 2015). This data set provided the declination $(D)$ and inclination $(I)$ values calculated on site using a magnetometer, along with the site's current latitude and longitude for each sample site (26 in total).

Through an Excel sheet, the paleolatitude $\left(\lambda_{s}\right)$ of each sample was calculated using Equation (17), and the pole latitude ( $\left.\lambda_{p}\right)$ of each was calculated using Equation (18). The pole longitude $\left(\phi_{p}\right)$ for each sample was calculated using Equations (19) and (20), depending on their $\cos (\theta)$ value (depicted by "longitude ambiguity test" on the Excel sheet) and on their longitudinal difference between their pole and site $(\beta)$, which was calculated using Equation (21). Each site contained about 8 to 10 samples, so each site's values were the average of every sample taken at that site. The final step recorded in the Excel sheet was the conversion of the polar values to Cartesian Pole Coordinates, which were done by:

$$
\text { (22) } \quad \text { North }=\cos \left(\text { pole latitude }{ }^{0}\right) \text {, }
$$

East $=\cos \left(\right.$ pole latitude $\left.\left({ }^{0}\right)\right) \sin \left(\right.$ pole longitude $\left({ }^{\circ}\right)$ and

$$
\text { West }=\cos \left(\text { pole latitude }\left({ }^{0}\right)\right) \cos \left(\text { pole longitude }\left({ }^{\circ}\right)\right. \text {. }
$$


The Fisher distribution is a type probability density function used in paleomagnetics to measure the probability of finding a direction within an area (Butler, 1992). Fisher distributions allow geophysicists to interpret data based on their sample's mean angle $(\theta)$, as it is a way to analyze the concentration of their data. The formula for the Fisher distribution is as follows: $P_{d A}(\theta)=\frac{\kappa}{4 \pi \sin (\kappa)} \exp (\kappa \cos (\theta))$. As shown in Figure 14, the more heavily concentrated the data is on the true angle mean $(\theta)$, the higher the Fisher precision parameter $(\kappa)$. As the Fisher precision parameter $(\kappa)$ approaches $\infty$, the calculations increase in precision (Butler, 1992). Due to the nature of $\kappa$, we can analyze the data set without performing an entire Fisher distribution. $\kappa$ can be found using the length of the combined vector $R$, shown in Equation (25):

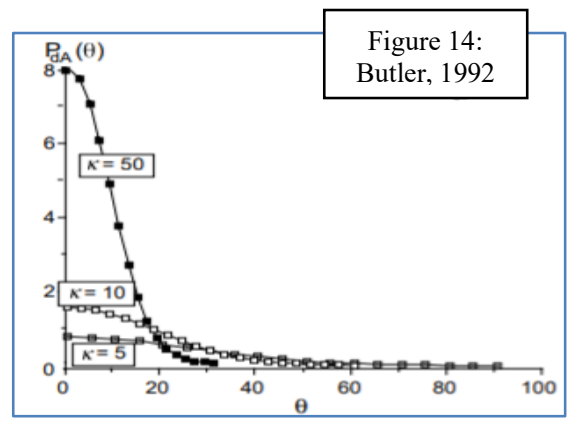

$$
R^{2}=\left(\sum_{i=1}^{n} \text { West }_{i}\right)^{2}+\left(\sum_{i=1}^{n} \text { East }_{i}\right)^{2}+\left(\sum_{i=1}^{n} \text { North }_{i}\right)^{2}
$$

(25) then $\sqrt{R^{2}}=R$.

After the combined vector $R$ is calculated, $\kappa$ can be found using this dispersion estimate (Butler, 1992).

$$
\text { (26) } \quad \kappa=\frac{n-1}{n-R}
$$

The angular standard deviation $(\delta)$ can be used to calculate the radius of a circle where $95 \%$ of the samples' coordinate points can be found (Butler, 1992).

$$
\text { If } \delta=\cos ^{-1}\left(\frac{R}{n}\right) \text {, then we can utilize, }
$$

$$
\alpha-95^{0}=\cos ^{-1}\left(1+\left((n-1) \frac{\left(1-20^{\frac{1}{n-1}}\right)}{(n(\kappa-1)+1)}\right)\left(\frac{180}{\pi}\right)\right) \text { to find the radius in degrees. }
$$

To find the exact location of the past geographic formation, the average pole paleolatitude and pole paleolongitude were found by calculating:

$$
\operatorname{mean}\left(\lambda_{p}\right)=\tan ^{-1}\left(\frac{\sum N}{\sqrt{(\Sigma W)^{2}+(\Sigma E)^{2}}}\right) \text { and }
$$

$$
\operatorname{mean}\left(\phi_{p}\right)=\text { if } \sum W>0, \text { then } \frac{\pi+\tan ^{-1} \frac{\sum E}{\sum W}}{\sum W}
$$


Finally, these average $\lambda_{p}$ and $\phi_{p}$ can be placed onto a map to show the past location of the sample itself based on the APW.

\section{DISCUSSION}

The declination $(D)$ and inclination $(I)$ were recorded by the magnetometer on site and the current latitude and longitude was recorded as $25^{\circ} 43^{\prime} 30^{\prime \prime} S 16^{0} 34^{\prime} 44^{\prime \prime} E$. The site paleolatitude $\left(\lambda_{s}\right)$, pole paleolatitude $\left(\lambda_{p}\right)$ and pole paleolongitude $\left(\phi_{p}\right)$ were calculated using Equations (18), (19) and (20) - these results are shown in Figure 15. The site paleolongitude (Longitude Ambiguity Test $\left(\phi_{S}\right)$ was also calculated using Equations (18-20) and is shown, along with the results for the longitudinal difference between pole and site $(\beta)$ in Figure 16. The Cartesian Pole Coordinates (N, W and E) were calculated using Equations (22-24) and are displayed in Figure 17.

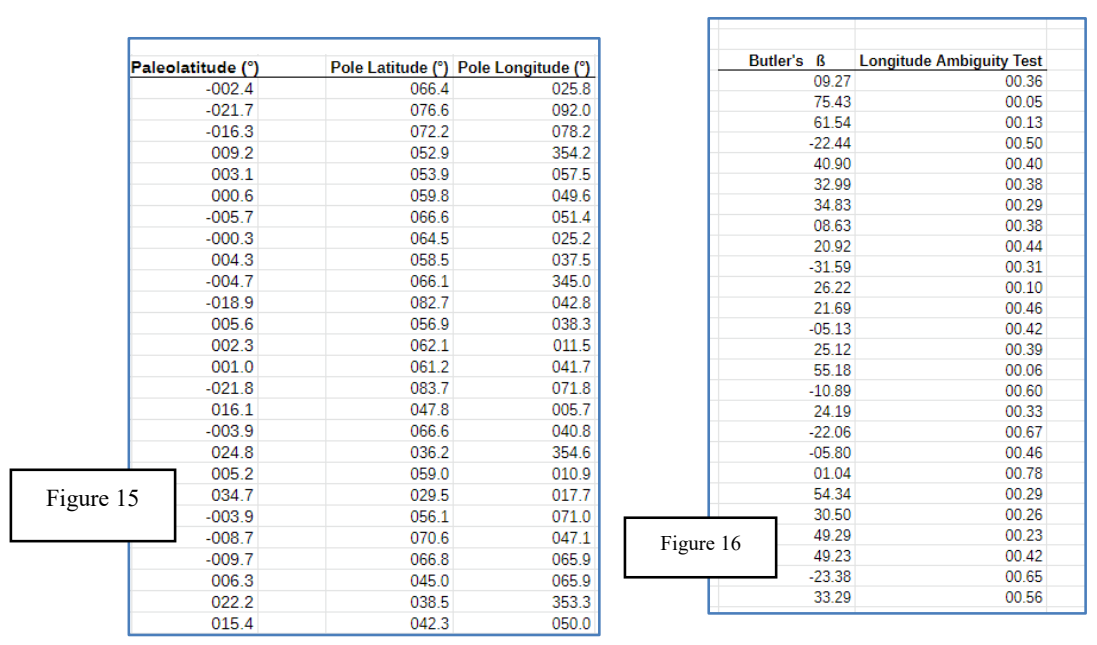

\begin{tabular}{|c|c|c|c|}
\hline \multicolumn{3}{|c|}{ Cartesian Pole Coordinates } & \\
\hline $\mathrm{N}$ & w & $E$ & \\
\hline 00.92 & 00.36 & 00.17 & \\
\hline 00.97 & -00.01 & 00.23 & \\
\hline 00.95 & 00.06 & 00.30 & \\
\hline 00.80 & 00.60 & -00.06 & \\
\hline 00.81 & 00.32 & 00.50 & \\
\hline 00.86 & 00.33 & 00.38 & \\
\hline 00.92 & 00.25 & 00.31 & \\
\hline 00.90 & 00.39 & 00.18 & \\
\hline 00.85 & 00.42 & 00.32 & \\
\hline 00.91 & 00.39 & -00.10 & \\
\hline 00.99 & 00.09 & 00.09 & \\
\hline 00.84 & 00.43 & 00.34 & \\
\hline 00.88 & 00.46 & 00.09 & \\
\hline 00.88 & 00.36 & 00.32 & \\
\hline 00.99 & 00.03 & 00.10 & \\
\hline 00.74 & 00.67 & 00.07 & \\
\hline 00.92 & 00.30 & 00.26 & \\
\hline 00.59 & 00.80 & -00.08 & \\
\hline 00.86 & 00.51 & 00.10 & \\
\hline 00.49 & 00.83 & 00.26 & \\
\hline 00.83 & 00.18 & 00.53 & \\
\hline 00.94 & 00.23 & 00.24 & \\
\hline 00.92 & 00.16 & 00.36 & Figure 17 \\
\hline 00.71 & 00.29 & 00.65 & \\
\hline 00.62 & 00.78 & -00.09 & \\
\hline 00.67 & 00.48 & 00.57 & \\
\hline
\end{tabular}

The sum vector $(R)$ was calculated to be $24.589=\sqrt{(21.76)^{2}+(9.71)^{2}+(5.47)^{2}}$. This $R$ value reveals that the data is rather accurate, since the number of sites $(n)$ was 26 and if $R=n$, then the calculations would be $100 \%$ accurate. $\kappa$ was calculated to be $17.712=\frac{26-1}{26-24.589}$. This $\kappa$ value reveals the preciseness of the data, since as $R$ approaches $26, \kappa$ becomes larger until it is undefined and the value of 17.712 is relatively large. Next, the radius that contains $95 \%$ of the samples' coordinate points $\left(\alpha-95^{\circ}\right)$ was calculated to be:

$$
6.93195^{0}=\cos ^{-1}\left(1+25\left(\frac{\left(1-20^{\frac{1}{25}}\right)}{26(16.712)+1}\right)\left(\frac{180}{\pi}\right)\right) .
$$

$95 \%$ of the found coordinates lying beneath a circle with a $6.93195^{\circ}$ radius shows that the calculations are accurate and precise, since this circle is relatively small. To determine the average coordinates (center of the circle), the final calculations were made using Equations (28) 
and (29). Figure 18 shows the results of the found average pole paleolatitude, $62.325^{0}$ $\left(62^{0} 19^{\prime} 30^{\prime \prime} N\right)$ and the average pole paleolongitude, $31.915^{\circ}\left(31^{0} 54^{\prime} 53^{\prime \prime} E\right)$. Figure 19 shows these coordinates plotted on a map - the green circle representing the $6.93195^{\circ}$ radius circle.
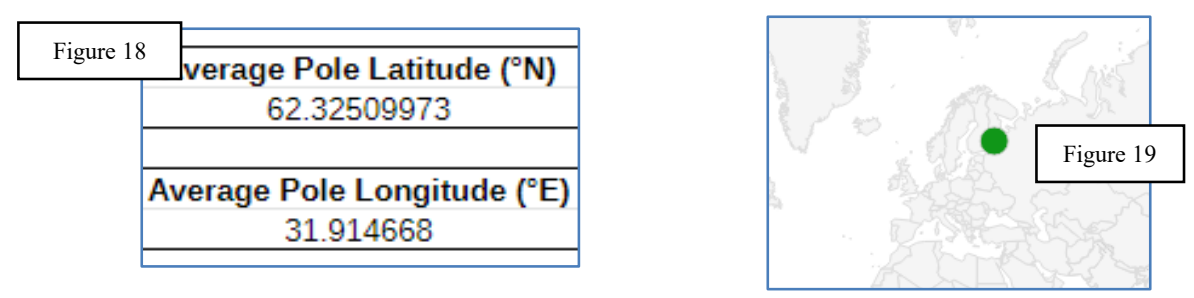

The calculations from the given data set revealed that the rock samples from the site located at $25^{\circ} 43^{\prime} 30^{\prime \prime} S 16^{0} 34^{\prime} 44^{\prime \prime} E$ present time (indicated in Figure 20 as green star), had preserved trace particles with a magnetic field that indicated the earth's pole being located at $62^{\circ} 19^{\prime} 30^{\prime \prime} N 31^{\circ} 54^{\prime} 53^{\prime \prime} E$ within a $6.93195^{\circ}$ radius circle uncertainty (indicated in Figure 19 and 20 by the green dot). We know that present day's north pole (blue circle in Figure 20) is located at $90^{\circ} 00^{\prime} 00^{\prime \prime} N 00^{\circ} 00^{\prime} 00^{\prime \prime} E$. From applying the GAD model through paleomagnetism, we know that this drastic change in pole location is not due to the movement of the pole, but the movement of the sample across the surface of Earth. From this analysis, we can state that these samples, found in southwest Namibia today, were near the coast of modern-day Mauritania and Western Sahara about 1.105 Gya (illustrated in Figure 20).

Figure 20

$\mathrm{N}$

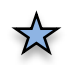

EQUATOR

Implications of Results 
The given data set's results, found through deconstructing the formulas used in paleomagnetism and analyzing the sample data using statistical analysis, revealed that the original site was once located near the coast of modern day Mauritania and Western Sahara during the Late Mesoproterozoic Era (1.105 Gya). When compared to literature surrounding this time, this information reveals that this was the location of southwest Africa during the preliminary formation of Rodinia, a supercontinent (McElhinny \& McFadden, 2000).

This process successfully fulfilled its original objective as the values of the magnetic information (location, declination, inclination) were able to be explained through trigonometry and partial derivatives, the derived equations were applied to collect more information on the sample site, a statistical analysis (using $R, \kappa$, and $\alpha-95^{\circ}$ ) was performed to analyze the data, and the role of the calculations was illustrated in Figure 20. These results, which showed the

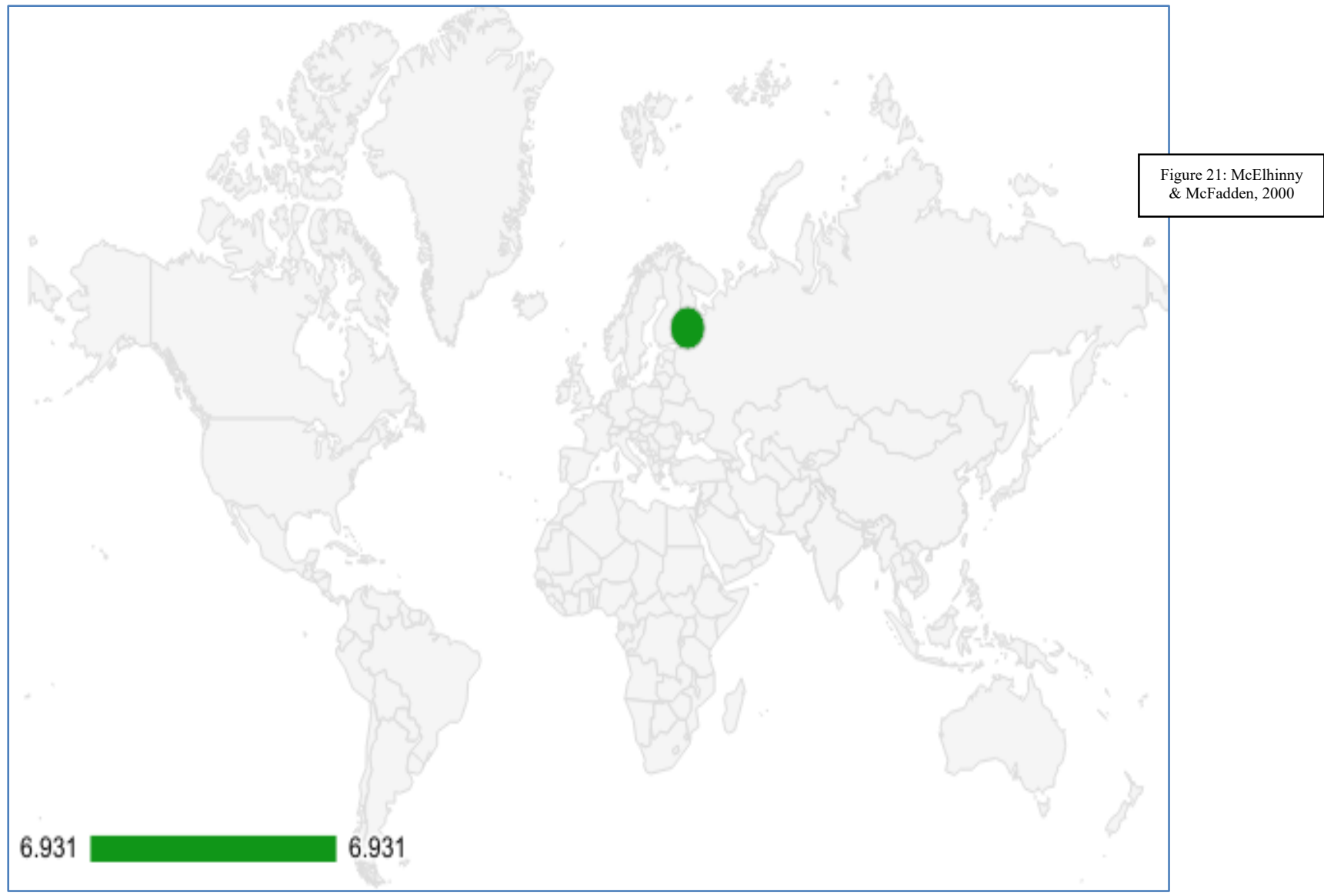

movement of the rock sample over the past billion years, were expected due to extensive evidence supporting continental drift and past data surrounding supercontinents dating back to the Late Mesoproterozoic Era (McElhinny \& McFadden, 2000). 
Although the original objectives were met, these results show how difficult the answer to this problem is - constructing past geographic formations requires many data points, across various locations on Earth to be relevant. Figure 21 shows an example of this - where thousands of data points were combined to show the movement of Laurentia from 1.10 Gya to .725 Gya (McElhinny \& McFadden, 2000).

This issue illustrates the importance of collaboration within the field of paleomagnetism. Alone, this dataset lacks context, as it only shows one area's change in location over a vast amount of time. Only when combined with numerous other data sets do the puzzle pieces begin to fit together.

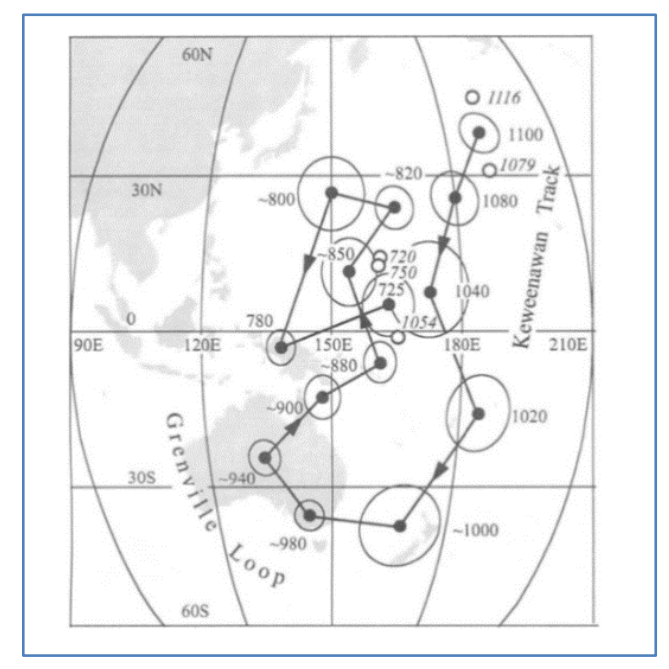

\section{CONCLUSION AND RECOMMENDATIONS}

The utilization of trigonometric functions, binomial coefficients, summations, and partial derivatives allows geophysicists to approach the task of accumulating data on past geographic formations on Earth. This has been demonstrated, using a given data set provided by Dr. Joseph Panzik on 26 sites in southwest Namibia, and deconstructing the steps taken to get to formulas used to find paleolongitude $\left(\phi_{p}, \phi_{s}\right)$ and paleolatitude $\left(\lambda_{p}, \lambda_{s}\right)$. The resulting calculations revealed that rock found at $25^{\circ} 43^{\prime} 30^{\prime \prime} S 16^{0} 34^{\prime} 44^{\prime \prime} E$ contains trace particles that have preserved information from the Late Mesoproterozoic Era (1.105 Gya) showing true north located at $62^{\circ} 19^{\prime} 30^{\prime \prime} N 31^{\circ} 54^{\prime} 53^{\prime \prime} E$. Based on paleomagnetism's assumption of GAD, this past pole location allows us to predict the past geographic location of this rock to be north of Namibia, near the coast of modern-day Mauritania and Western Sahara (northwest Africa). These results correlated with past literature on the formation of Rodinia (the supercontinent beginning to form at 1.105 Gya). Although this shows that this method is reliable, it also highlights the need for more data, as the given data only reveals the location of one extremely specific location, at one time in Earth history.

In the future, one may consider assessing accumulated data from other studies for further study. The next step in paleomagnetism, after the retrieval of data points from a site, is to compare what you have found with other data and piece together the geographic formations. Being able to appropriately fit your data into the large-scale scheme of continental drift is crucial in paleomagnetism, since it is what allows your data to become relevant on a larger scale. This problem involves a higher level of statistical analysis and the communication of results between varying fields. Examples of potential statistical analysis methods to further explore with the use 
of calculus would be a demonstration of the fold test (comparing variance and $\kappa$ between differing data sets) and a full Fisher distribution assessment (Butler, 1992). The consideration of how calculus applies to that aspect of paleomagnetism would be extremely beneficial.

\section{NOMENCLATURE}

\begin{tabular}{|c|c|c|}
\hline Symbol & Description & Units (SI) \\
\hline$\vec{M}$ & Magnetization & $A m^{-1}$ \\
\hline$\vec{H}$ & Magnetic Field & $A m^{-1}$ \\
\hline$\vec{B}$ & Magnetic Induction & $T$ \\
\hline$\mu_{0}$ & Permeability of free space & $H m^{-1}$ \\
\hline$\Psi_{m}$ & Magnetic potential & $A$ \\
\hline$\theta$ & Co-latitude (angle from N pole) & degrees $\left({ }^{0}\right)$ \\
\hline$\phi$ & longitude & degrees $\left({ }^{0}\right)$ \\
\hline$\lambda$ & Latitude & degrees $\left({ }^{0}\right)$ \\
\hline$\beta$ & Longitudinal difference between site and pole & degrees $\left({ }^{0}\right)$ \\
\hline$\kappa$ & Fisher precision parameter & degrees $\left({ }^{0}\right)$ \\
\hline$\alpha-95^{0}$ & angular standard deviation (with $95 \%$ confidence) & degrees $\left({ }^{0}\right)$ \\
\hline Gya & Billion years ago (gigaannum) & $10^{9}$ years ago \\
\hline
\end{tabular}

\section{REFERENCES}

Barendregt, R. W., Enkin, R. J., \& Duk-Rodkin, A. (2010). Paleomagnetic evidence for multiple late cenozoic glaciations in the tintina trench, westcentral yukon, canada doi:10.1139/E10-021

Butler, R. F. (1992). PALEOMAGNETISM: Magnetic Domains to Geologic Terranes. Retrieved from https://www.geo.arizona.edu/Paleomag/ 
Campbell, J. (2017). Magnetic force Salem Press. Retrieved from http://ezproxy.lib.usf.edu/login?url=http://search.ebscohost.com/login.aspx?direct $=$ true $\& \mathrm{db}=$ ers $\& A N=87996257 \&$ site $=$ eds-live

McElhinny, M. W., \& McFadden, P. L. (2000). Paleomagnetism: Continents and oceans. San Diego: Academic Press. Retrieved from http://ezproxy.lib.usf.edu/login?url=http://search.ebscohost.com/login.aspx?direct=true $\& \mathrm{db}=$ nlebk $\& \mathrm{AN}=205642 \&$ site $=$ eds-live

Panzik, J. E., Evans, D. A. D., Kasbohm, J. J., Hanson, R., Gose, W., \& Desormeau, J. (2015). Using palaeomagnetism to determine late Mesoproterozoic palaeogeographic history and tectonic relations of the Sinclair terrane, Namaqua orogen, Namibia. Geological Society, London, Special Publications, 424(1), 119-143. doi: $10.1144 / \mathrm{sp} 424.10$

Prothero, D. R. (2018). The story of the earth in 25 rocks: Tales of important geological puzzles and the people who solved them. New York: Columbia University Press.

Retrieved from http://ezproxy.lib.usf.edu/login?url=http://search.ebscohost.com/login.aspx?direct $=$ true $\& \mathrm{db}=$ nlebk $\& A N=1662838 \&$ site $=$ eds-live

Tauxe, L., Butler, R. F., Van der Voo, R., \& Banerjee, S. K. (2010). Essentials of paleomagnetism (1st ed. ed.) University of California Press. Retrieved from http://ezproxy.lib.usf.edu/login

Urry, L. A., Cain, M. L., Wasserman, S. A., Minorsky, P. V., Orr, R. B., \& Campbell, N. A. (2020). Campbell biology. New York, NY: Pearson. 


\section{APPENDICES}

- This data is from Namibia, Africa. Collected by J.E. Panzik, J. Kasbohm, J. Hessert, and S. Darroch during June-August 2011 \& 2012

- Data is from dike swarms that were emplaced after the Guperas Formation

\begin{tabular}{|c|c|c|c|c|c|c|c|c|c|c|c|c|c|}
\hline & \multirow[b]{2}{*}{ Site Name } & \multirow[b]{2}{*}{ Declination $\left({ }^{\circ}\right)$} & \multirow[b]{2}{*}{ Inclination $\left({ }^{\circ}\right)$} & \multirow[b]{2}{*}{ Lat $\left({ }^{\circ} \mathbf{N}\right)$} & \multirow[b]{2}{*}{ Long $\left({ }^{\circ} \mathbf{E}\right)$} & \multirow[b]{2}{*}{$\begin{array}{c}\text { Paleolatitude } \\
\left({ }^{\circ}\right) \\
\end{array}$} & \multirow[b]{2}{*}{$\begin{array}{c}\text { Pole } \\
\text { Latitude } \\
\left({ }^{\circ}\right) \\
\end{array}$} & \multirow[b]{2}{*}{$\begin{array}{c}\text { Pole } \\
\text { Longitude } \\
\left({ }^{\circ}\right) \\
\end{array}$} & \multirow[b]{2}{*}{ Butler's B } & \multirow[b]{2}{*}{$\begin{array}{c}\text { Longitude } \\
\text { Ambiguity } \\
\text { Test } \\
\end{array}$} & \multicolumn{3}{|c|}{$\begin{array}{c}\text { Cartesian Pole } \\
\text { Coordinates }\end{array}$} \\
\hline & & & & & & & & & & & $\mathbf{N}$ & W & $\mathbf{E}$ \\
\hline $\begin{array}{c}\text { Average Pole } \\
\text { Latitude }\end{array}$ & JP1101 & 003.7 & -04.8 & -25.7 & 016.6 & -002.4 & 066.4 & 025.8 & 09.27 & 00.36 & 00.92 & 00.36 & 00.17 \\
\hline \multirow[t]{2}{*}{62.32509973} & Cluster 1 & 014.0 & -38.5 & -25.7 & 016.6 & -021.7 & 076.6 & 092.0 & 75.43 & 00.05 & 00.97 & -00.01 & 00.23 \\
\hline & Cluster 2 & 016.3 & -30.4 & -25.7 & 016.6 & -016.3 & 072.2 & 078.2 & 61.54 & 00.13 & 00.95 & 00.06 & 00.30 \\
\hline $\begin{array}{c}\text { Average Pole } \\
\text { Longitude }\end{array}$ & Cluster 3 & 346.5 & 18.0 & -25.5 & 016.6 & 009.2 & 052.9 & 354.2 & -22.44 & 00.50 & 00.80 & 00.60 & -00.06 \\
\hline \multirow[t]{2}{*}{31.914668} & JP1111 & 022.7 & 06.2 & -25.5 & 016.6 & 003.1 & 053.9 & 057.5 & 40.90 & 00.40 & 00.81 & 00.32 & 00.50 \\
\hline & JP1112 & 015.9 & 01.1 & -25.5 & 016.6 & 000.6 & 059.8 & 049.6 & 32.99 & 00.38 & 00.86 & 00.33 & 00.38 \\
\hline $\mathrm{A}-95\left(^{\circ}\right)$ & JP1113 & 013.2 & -11.3 & -25.5 & 016.6 & -005.7 & 066.6 & 051.4 & 34.83 & 00.29 & 00.92 & 00.25 & 00.31 \\
\hline \multirow[t]{2}{*}{6.93102907} & JP1114 & 003.7 & -00.5 & -25.5 & 016.6 & -000.3 & 064.5 & 025.2 & 08.63 & 00.38 & 00.90 & 00.39 & 00.18 \\
\hline & JP1115 & 010.8 & 08.5 & -25.5 & 016.6 & 004.3 & 058.5 & 037.5 & 20.92 & 00.44 & 00.85 & 00.42 & 00.32 \\
\hline $\begin{array}{l}\text { Number of Sites } \\
\text { (N) }\end{array}$ & JP1117 & 347.7 & -09.3 & -25.5 & 016.6 & -004.7 & 066.1 & 345.0 & -31.59 & 00.31 & 00.91 & 00.39 & -00.10 \\
\hline \multirow[t]{5}{*}{26} & Cluster 4 & 003.4 & -34.4 & -25.5 & 016.6 & -018.9 & 082.7 & 042.8 & 26.22 & 00.10 & 00.99 & 00.09 & 00.09 \\
\hline & JP1120 & 011.7 & 11.1 & -25.5 & 016.6 & 005.6 & 056.9 & 038.3 & 21.69 & 00.46 & 00.84 & 00.43 & 00.34 \\
\hline & JP1121 & 357.6 & 04.6 & -25.5 & 016.6 & 002.3 & 062.1 & 011.5 & -05.13 & 00.42 & 00.88 & 00.46 & 00.09 \\
\hline & JP1122 & 011.8 & 01.9 & -25.5 & 016.6 & 001.0 & 061.2 & 041.7 & 25.12 & 00.39 & 00.88 & 00.36 & 00.32 \\
\hline & JP1123 & 005.6 & -38.6 & -25.5 & 016.6 & -021.8 & 083.7 & 071.8 & 55.18 & 00.06 & 00.99 & 00.03 & 00.10 \\
\hline $\mathbf{K}$ & JP1125 & 352.4 & 30.0 & -25.5 & 016.6 & 016.1 & 047.8 & 005.7 & -10.89 & 00.60 & 00.74 & 00.67 & 00.07 \\
\hline \multirow[t]{6}{*}{17.71172105} & JP1126 & 009.4 & -07.7 & -25.5 & 016.6 & -003.9 & 066.6 & 040.8 & 24.19 & 00.33 & 00.92 & 00.30 & 00.26 \\
\hline & JP1127 & 340.5 & 42.8 & -25.5 & 016.6 & 024.8 & 036.2 & 354.6 & -22.06 & 00.67 & 00.59 & 00.80 & -00.08 \\
\hline & JP1140 & 357.0 & 10.3 & -25.7 & 016.7 & 005.2 & 059.0 & 010.9 & -05.80 & 00.46 & 00.86 & 00.51 & 00.10 \\
\hline & JP1144 & 001.1 & 54.2 & -25.7 & 016.7 & 034.7 & 029.5 & 017.7 & 01.04 & 00.78 & 00.49 & 00.83 & 00.26 \\
\hline & JP1147 & 027.0 & -07.7 & -25.7 & 016.6 & -003.9 & 056.1 & 071.0 & 54.34 & 00.29 & 00.83 & 00.18 & 00.53 \\
\hline & Cluster 5 & 009.8 & -17.1 & -25.7 & 016.6 & -008.7 & 070.6 & 047.1 & 30.50 & 00.26 & 00.94 & 00.23 & 00.24 \\
\hline $\begin{array}{c}\text { Radian } \\
\text { Conversion }\end{array}$ & Cluster 6 & 017.6 & -18.8 & -25.7 & 016.6 & -009.7 & 066.8 & 065.9 & 49.29 & 00.23 & 00.92 & 00.16 & 00.36 \\
\hline \multirow[t]{3}{*}{0.01745329252} & JP1211 & 032.6 & 12.4 & -25.7 & 016.6 & 006.3 & 045.0 & 065.9 & 49.23 & 00.42 & 00.71 & 00.29 & 00.65 \\
\hline & JP1216 & 340.4 & 39.2 & -25.7 & 016.7 & 022.2 & 038.5 & 353.3 & -23.38 & 00.65 & 00.62 & 00.78 & -00.09 \\
\hline & JP1217 & 024.9 & 28.8 & -25.7 & 016.7 & 015.4 & 042.3 & 050.0 & 33.29 & 00.56 & 00.67 & 00.48 & 00.57 \\
\hline
\end{tabular}

